\title{
Uporaba markovskih verig za zasnovo scenarija razvoja kulturne krajine
}

Scenariji so orodje, ki se vse pogosteje uporablja na področju krajinskega in prostorskega načrtovanja, saj omogoča jasno predstavitev mogočega ali želenega prihodnjega stanja na določenem območju. Pri izdelavi scenarijev se uporablja različno razmerje intuicije in raziskovalnega dela. Prednost scenarija, ki je zasnovan na podlagi raziskovalnega dela in določene metode, je razviden postopek oziroma časovni potek sprememb ter ne samo začetno in končno stanje kot pri scenariju, ki je rezultat intuitivnega postopka. $V$ članku podrobneje predstavljamo metodo markovskih verig in njeno uporabo za zasnovo scenarija, primerjamo uporabnost me- tode in njene rezultate $\mathrm{z}$ enostavnejšo metodo linearne ekstrapolacije ter na kratko predstavljamo ugotovitve iz izbranih primerov uporabe markovskih verig za prikaz prihodnjih prostorskih sprememb oziroma procesov.

Ključne besede: scenarij razvoja kulturne krajine, metodologija zasnove scenarijev, markovske verige 


\section{Uvod}

Na področju krajinskega načrtovanja se pojem scenarij nanaša na različne verjetne zgodbe ali alternativne domneve, ki prikazujejo prihodnje spremembe krajine. Spremembe krajine so navadno prikazane prek spremembe rabe tal, ki se posledično kaže tudi kot spremenjen vzorec talnega pokrova (Steinitz idr., 2003). Pojem scenarij je za poimenovanje dolgoročnih vizij prihodnosti prvi uporabil Herman Kahn leta 1950 in v širšem pomenu združuje različne tehnike oziroma študije, usmerjene $\mathrm{v}$ proučevanje prihodnosti, kot so analize trendov, napovedi, variantne analize in strategije (Shearer, 2005). Obstaja veliko različnih definicij, ki so prilagojene posameznim oblikam in uporabi scenarijev. Ožjo definicijo sta postavila van den Berg in Veeneklaas (1995: 11): »Scenarij je opis ali podoba sedanjega stanja, verjetnega ali želenega prihodnjega stanja in tudi serije dogodkov, ki vodijo od sedanjega do tega želenega ali verjetnega prihodnjega stanja.« Drugo definicijo, s katero lahko prav tako predstavimo scenarije razvoja kulturne krajine in njihovo uporabo v načrtovalskem postopku, je opredelil Shoemaker (1993: 196): »Scenariji stimulirajo kreativne načine razmišljanja, ki pomagajo deležnikom nadgraditi ustaljene načine ocenjevanja okoliščin in načrtovanja delovanja ter se lahko tako bolje prilagodijo na prihodnost. « Če bi obe definiciiji združili, bi zaobjeli scenarij, ki je rezultat raziskovalno metode, predstavljene v članku, in hkrati izrazili učinek scenarija na deležnike.

Pri zasnovi scenarijev se raziskovalci gibljejo med dvema skrajnostma. Zasnova scenarijev je lahko povsem prepuščena intuitivnemu procesu razmišljanja, tako imenovana črna škatla (ang. black box), ali pa sledi natančno določenim postopkom oziroma modelu. Prednost scenarija, ki je rezultat takega postopka, je razvidna pot, ki nas je pripeljala do končnega rezultata, ne pa samo začetno in končno stanje kot pri intuitivni zasnovi scenarija.

Uporaba markovskih verig pri zasnovi scenarija je podlaga za prikaz dinamike sprememb v kulturni krajini, ki se bodo zgodile v prihodnosti. Razvoj kulturne krajine v predstavljenem scenariju smo opredelili z verjetnimi spremembami rabe tal, izračunanimi $\mathrm{z}$ uporabo markovskih verig in $\mathrm{z}$ upoštevanjem vplivov gonilnih sil oziroma različnih razvojnih dejavnikov na spreminjanje. Med gonilnimi silami so tudi določene politike. Upoštevanje politik je pomembno s stališča varovanja (varstvena območja, rezervati, $v$ katerih so omejitve obvezujoče in natančno določene) in stališča spodbujanja razvoja (spodbude ali odločitve za določene načine delovanja v prostoru). Pri opredelitvi sprememb je pomembno tudi poznavanje zakonitosti prehajanja med posameznimi vrstami rabe, na primer: zaraščajoče površine se ne spremenijo $\mathrm{v}$ gozd $\mathrm{v}$ enem koraku oziroma sekvenci, sprememba travnika v pozidano zemljišče pa se lahko zgodi v zelo kratkem času in je le težko oziroma načeloma ni reverzibilna. Čas, ki ga določene rabe potrebujejo za prehod iz ene rabe v drugo, je odvisen od pritiska po spremembi rabe in lastnosti določenega prostora oziroma okoliščine.

Markovske verige se sicer uporabljajo v različnih vejah znanosti, pogosteje v naravoslovnih vedah, vendar tudi v družboslovju, geografiji, ekologiji. V prostorskih vedah se markovske verige uporablja za reševanje problemov, povezanih z gibanjem $\mathrm{v}$ prostoru ali času oziroma iz enega stanja v drugo. Markovske verige se uporablja za opisovanje, analiziranje in napovedovanje razvoja pojavov, kot so zaposlovanje, migracije, rast in razvoj urbanih sistemov in spremembe v rabi krajine (npr. Omladič, 1993; Mežan, 1995). Na področju preučevanja razvoja prostora oziroma za načrtovanje razvoja je bila za Ljubljano izdelana raziskovalna naloga, z naslovom Uporaba markovskih verig za analizo rasti in upadanja poselitve v ljubljanskem urbanem območju (ang. An aplication of Markov chains to the analysis of the growth and decline of settlements in the Ljubljana metropolitan area) (Lawson, 1970). Študija je sicer starejša, vendar je z metodološkega vidika koristna, saj poskuša na podlagi preteklih teženj prostorskega razvoja mesta napovedati nadaljnji razvoj $s$ pomočjo markovskih verig. Primer uporabe markovskih verig pri izdelavi scenarijev je predstavljen v raziskovalni nalogi, z naslovom Modeliranje prihodnje rabe zemljišč na območju Surselve (nem. Modelierung der zukünftigen Landnutzung in der Surselva) (Stadelmann in Weiss, 2007), podobno so k zasnovi scenarijev pristopili tudi U. Tappeiner idr. (2007). Na primeru Slovenije so uporabo markovskih verig in podpore odločanja proučevali Kovačič idr. (2007).

\section{Opis metode}

\subsection{Markovski procesi}

»Stohastični ali slučajni procesi so procesi, ki se spreminjajo s časom ali krajem v skladu z zakoni verjetnosti. Veliko realnih procesov kaže značilnosti stohastičnih procesov, zato je poznavanje njihovega mehanizma pomembno za razumevanje situacij, ki v praksi nastopajo « (Hudoklin-Božič, 1999: 5). Markovske verige, markovski model (tudi model Markova) in skriti model Markova sodijo med stohastične procese. Osnovna načela markovskih verig je uvedel Andrej Andrejevič Markov (1856-1922), ruski matematik, ki se je ukvarjal s teorijo števil, $\mathrm{z}$ verjetnostnim računom, $s$ teorijo stohastičnih procesov in z matematično analizo (Basharin idr., 2005).

Osnovni markovski proces je markovska veriga, zaporedje $x_{1}, x_{2}, x_{3}, \ldots$ diskretnih slučajnih spremenljivk, $\mathrm{v}$ katerem je prva naslednja spremenljivka $x_{n}$ odvisna le od tega, kakšno 
vrednost ima spremenljivka $x_{n-1}$ pri $n=2,3,4, \ldots$ (Lawson, 1970). Pri markovskem procesu je pogojna verjetnostna porazdelitev spremenljivke $x_{m}$ odvisna le od najpoznejšega znanega stanja in ne od stanj procesa v preǰ̌njih časih. Markovski proces $»$ nima spomina «, za napoved obnašanja procesa v prihodnosti je treba poznati sedanjost in ne preteklosti. Ali je proces markovski ali ne, je odvisno od definicije slučajnih spremenljivk, ki določajo proces. Velikokrat lahko nemarkovski proces pretvorimo v markovski, če definiramo prostor stanj tako, da velja markovska lastnost (Hudoklin-Božič, 1999):

Proces je markovski v diskretnem času, če za poljubne čase $l<m<n$ velja, da je pogojna verjetnostna porazdelitev slučajne spremenljivke $x_{n}$ odvisna le od najpoznejšega znanega stanja in ne od stanj procesa $\mathrm{v}$ prejšnjih časih.

$\operatorname{Px}_{\mathrm{n}}\left(\mathrm{x} \mid \mathrm{X}=\mathrm{y}, \mathrm{X}_{1}=\mathrm{z}, \ldots\right)=\operatorname{Px}_{\mathrm{n}}\left(\mathrm{x} \mid \mathrm{X}_{\mathrm{m}}=\mathrm{y}\right)$

Markovske verige so markovski procesi z diskretnimi stanji v diskretnem času, poleg tega obstajajo tudi markovski procesi z diskretnimi stanji v zveznem času. Pri markovskih verigah je število stanj lahko končno ali števno neskončno. Markovska veriga je množica diskretnih slučajnih spremenljivk $\left\{x_{n}\right\}, n=0,1, \ldots$, ki imajo to lastnost: če poznamo vrednost $x_{m} \mathrm{v}$ poljubnem trenutku $m$, je $\mathrm{v}$ nekem poznejšem trenutku $m+n$ verjetnostna porazdelitev $x_{m+n}$ popolnoma določena (Hudoklin-Božič, 1999).

$P\left(X_{m+n}=j \mid X_{m}=i, X_{m-1}=h, X_{m-2}=g, \ldots\right)=P\left(X_{m+n}=j \mid X_{m}=i\right)$

Markovske verige so časovno homogene, če je pogojna verjetnost $\mathrm{P}$ odvisna le od širine časovnega intervala $n$ in ne od časa $m$. Velja relacija:

$P\left(X_{m+n}=j \mid X_{m}=i\right)=P\left(X_{n}=j \mid X_{0}=i\right)$

$\mathrm{m}=1,2 \ldots ; \quad \mathrm{n}=1,2, \ldots$

Pogojno verjetnost, da je bilo na začetku opazovanja zasedeno stanje $i$ in v času $n$ stanje $j$, imenujemo verjetnost prehoda iz stanja $i$ v $j$ v času $n$ ( $n$ korakih) in jo označimo s simbolom $\mathrm{p}_{\mathrm{ij}}^{(\mathrm{n})}$.

$\mathrm{p}_{\mathrm{ij}}^{(\mathrm{n})}=\left(\mathrm{X}_{\mathrm{m}+\mathrm{n}}=\mathrm{j} \mid \mathrm{X}_{\mathrm{m}}=\mathrm{i}\right)$

Verjetnost prehoda v enem koraku $p_{i j}$ je verjetnost, da bo spremenljivka iz razreda $i$ v časovni enoti prešla v razred $j$ oziroma se ji bo vrednost spremenila iz $i v j$. Pri končni markovski verigi s prostorom stanj $S=\{0,1, \ldots N\}$ je $(N+1)^{2}$ verjetnosti prehodov iz enega stanja verige v drugo. Te verjetnosti najprimerneje zapišemo v obliki matrike.

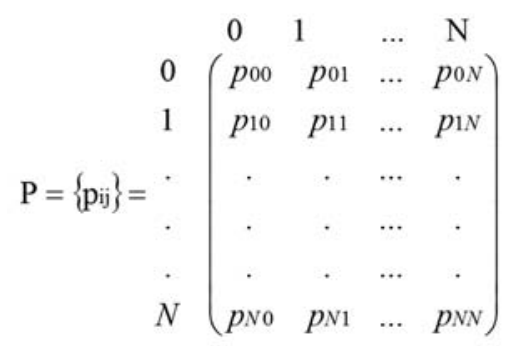

Matrika P je prehodna matrika, začetna stanja se spreminjajo po vrsticah, končna pa po stolpcih matrike. Prehodna matrika vsebuje vse potrebne informacije o prehodih verige med stanji v prostoru stanj $S$. Matrika je stohastična, kar pomeni, da so vsi elementi nenegativni, vsota členov v posamezni vrstici je enaka 1 (verjetnost je enaka 1), matrika je kvadratna (Hudoklin-Božič, 1999). Če je matrika $P$ konstantna, je markovska veriga homogena, prehodne vrednosti pa stacionarne.

Za elemente matrike P velja:

$\sum_{j} p_{i j}=1 \quad 0 \leq \mathrm{p}_{\mathrm{ij}} \leq 1 \quad \mathrm{i}=1,2, \ldots \mathrm{N}$.

Matrika $\mathrm{P}$ in začetna porazdelitev verjetnosti

$\mathrm{P}(0)=\left(\mathrm{p}_{\mathrm{i}}^{(\mathrm{n})}, \mathrm{p}_{\mathrm{i}}^{(\mathrm{n})}, \mathrm{p}_{\mathrm{i}}^{(\mathrm{n})}\right) \quad 0 \leq \mathrm{p}_{\mathrm{i}} \leq 1 \quad \mathrm{i}=1,2, \ldots \mathrm{N}$

popolnoma določata verjetnostne lastnosti homogene markovske verige. Vrstični vektor

$\mathrm{p}(\mathrm{n})=\left(\mathrm{p}_{1}{ }^{(\mathrm{n})}, \mathrm{p}_{2}{ }^{(\mathrm{n})}, \mathrm{p}_{\mathrm{N}}{ }^{(\mathrm{n})}\right) \quad 0 \leq \mathrm{p}_{\mathrm{i}} \leq 1 \quad \mathrm{i}=1,2, \ldots \mathrm{N}$

pove, kolikšne so verjetnosti, da je sistem po $n$ korakih v stanju $i$ (Jamnik, 1987).

\subsection{Zasnova scenarija $z$ uporabo markovskih verig}

Od osnovnih značilnosti markovskih verig prehajamo na aplikacijo te metode v primeru izdelave scenarija za testno območje Godovič-Črni Vrh v občini Idrija. Raziskava je bila izvedena v okviru doktorskega dela, z naslovom Scenariji razvoja kulturne krajine kot dejavnik spreminjanja stalǐ̌̌c deležnikov ${ }^{[1]}$ (Gantar, 2009). Posebej nas je zanimala določitev prehodne matrike za testno območje na podlagi osnovne matrike P. Opredelitev prehodne matrike je podlaga za preverjanje verjetnosti sprememb posameznih rab v testnem območju in deležev območij spreminjanja posameznih rab v določenem obdobju. Za uporabo metode smo se odločili tudi zaradi značilnosti dosegljivih prostorskih podatkov za testno območje. Bistveno vodilo za izbiro podatkov je bila njihova prostorska natančnost in dosegljivost medsebojno primerljivih podatkov za (najmanj) dve časovni obdobji. 
Za oceno sprememb v kulturni krajini po posameznih rabah sta pomembna podatka o medsebojni prehodnosti rab (ang. conversion elasticity) in o prehodnih stanjih posameznih rab (ang. land use transition sequences) (Lawson, 1970). Medsebojna prehodnost rab se kaže predvsem v zmožnosti posamezne rabe, da se bo spremenila v določeno drugo rabo, in tudi možnosti, da se bo zatem povrnila v prvotno rabo. Navadno se rabe, pri katerih so vložki kapitala in dela veliki, na primer, pozidava in trajni nasadi, težje in počasneje spreminjajo. Druge rabe tal, kot na primer travniki, se lahko razmeroma hitro spremenijo $\mathrm{v}$ urbano rabo, spremembe med gozdom in travniki oziroma kmetijsko rabo pa se nenehno dogajajo predvsem ob gozdnem robu. Prehodnost rab se opredeli z vrednostjo med 0 (lahko prehajanje) in 1 (nepovraten prehod). Vrednost se navadno opredeli na podlagi strokovnega znanja in opazovanj (slika 1).
Preglednico 1, v kateri so spremembe površin za posamezne vrste rabe izračunane po metodi linearne ekstrapolacije, lahko uporabljamo le kot okvirno usmeritev, ki nas bolj kot na dejansko mogoče spremembe opozarja na napake, ki pri napovedovanju prihodnjih sprememb nastanejo, če upoštevamo samo težnje, ki so bile značilne za preteklo obdobje. V predstavljenem primeru rezultati niso zanesljivi, ker gre za relativno kratko obdobje. Linearna ekstrapolacija predvideva, da se težnja, ki je veljala med letoma 1998 in 2006, linearno nadaljuje v prihodnosti. Izračun je bil opravljen po korakih, $s$ prikazom sprememb po letih, za objavo povzemamo le začetne in končne vrednosti. Iz rezultatov sledi, da uporabljena metoda ni ustrezna, saj pri nekaterih rabah prihodnje vrednosti za površine že postanejo negativne. Sledi ugotovitev, da gibanja pri večini rab niso linearna. Žal pa zaradi podatkov za samo

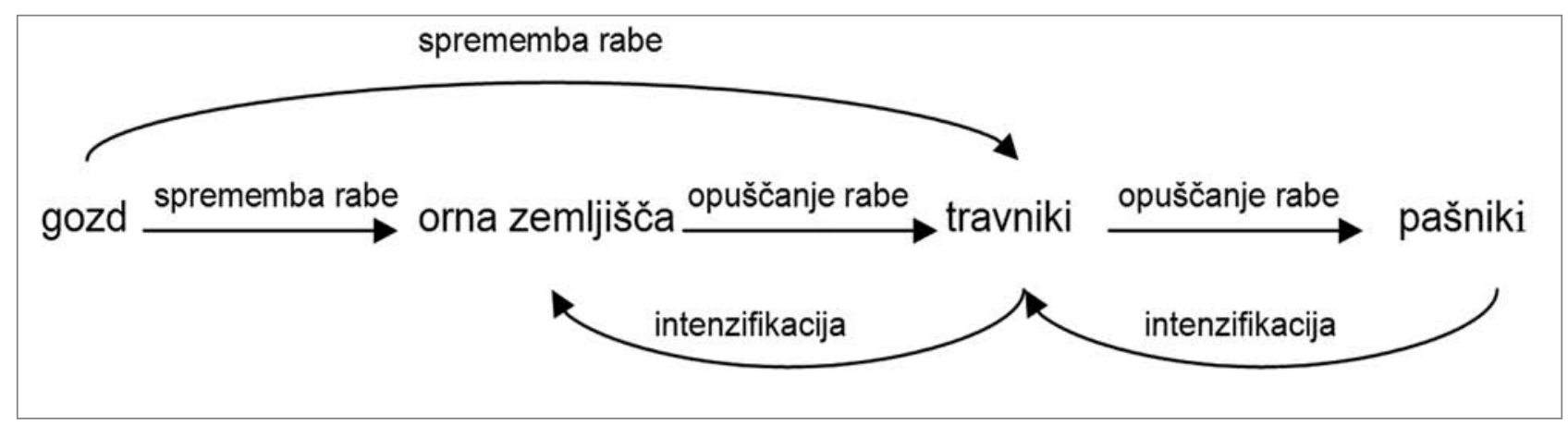

Slika 1: Shema spreminjanja rabe tal po korakih

Najprej smo preverili smiselnost domneve o konstantnem spreminjanju rabe tal z uporabo metode linearne ekstrapolacije. Spremembe kategorij vrste rabe tal med letoma 1998 in 2007, pridobljene iz podatkov o dejanski rabi tal (Ministrstvo RS za kmetijstvo, gozdarstvo in prehrano, 1998, 2006a) smo neposredno ekstrapolirali - prenesli v prihodnost in dobili vrednosti sprememb za naslednjih 15 let. Pri tem predvidevamo, da so vse spremembe vrst rabe konstantne (preglednica 1).

Preglednica 1: Napoved sprememb posameznih vrst rabe tal za 15 let po metodi linearne ekstrapolacije

\begin{tabular}{lcc}
\hline Vrsta rabe $\left(\mathrm{m}^{2}\right)$ & Leto 2006 & Leto 2021 \\
\hline Njive in vrtovi & $316.420,12$ & $-240.675,08$ \\
\hline Ekstenzivni sadovnjaki & $110.284,32$ & $127.452,72$ \\
\hline Trajni travniki & $16.980 .397,73$ & $17.043 .431,18$ \\
\hline Zemljišča v zaraščanju & $677.216,96$ & $699.262,70$ \\
\hline Neobdelana kmet. zemljišča & $34.839,45$ & $-16.810,65$ \\
\hline Kmetijske površine porasle z & $146.574,96$ & $-155.480,19$ \\
gozdnim drevjem & $562.868,21$ & $860.028,86$ \\
\hline Drevesa in grmičevje & $62.983 .163,81$ & $63.326 .461,61$ \\
\hline Gozd & $2.369 .026,25$ & $2.244 .325,85$ \\
\hline Pozidana in sorodna zemljišča
\end{tabular}

Vir: Ministrstvo RS za kmetijstvo, gozdarstvo in prehrano $(1998,2006 a)$ dve leti in v relativno kratkem časovnem obdobju ne moremo opredeliti, za kakšno gibanje gre.

\subsection{Izbor in priprava vhodnih podatkov za izdelavo scenarija}

Prvi korak pri izdelavi scenarija po metodi markovskih verig je izbira ustreznih vhodnih podatkov. Podatke o dejanski rabi tal je mogoče pridobiti iz različnih virov, za čim večjo natančnost, ki jo potrebujemo pri analizi rabe tal pri tako majhnem testnem območju, je smiselna uporaba podatkov, izdelanih na podlagi letalskih snemanj. Za izdelavo matrike prehodov (po markovskih verigah) so bili uporabljeni podatki o dejanski rabi tal ministrstva za kmetijstvo, gozdarstvo in prehrano iz katastra dejanske rabe kmetijskih zemljišč. Časovno primerjavo nam zagotavljajo podatki iz leta 1998 in 2006, ki imajo primerljivo klasifikacijo vrst rabe. Podatki so bili izdelani na podlagi digitalnih ortofoto načrtov v merilu $1: 5000$, izdelanih na osnovi aeroposnetkov merila od $1: 15.000$ do $1: 25.000$, slikovni element je velik $0,5 \mathrm{~m}$ (ena celica je velika $0,25 \mathrm{~m} 2$ ). Podatek o dejanski rabi je razdeljen na štiriindvajset kategorij vrst rabe. Pri izdelavi scenarijev smo upoštevali devet kategorij vrst rabe, ki obstajajo v testnem območju in so bile klasificirane v obeh omenjenih zajemih podatkov. 
Preglednica 2: Podatki za dejansko rabo kmetijskih zemljišč za testno območje za leti 1998 in 2006 ter izračunana sprememba v odstotkih

\begin{tabular}{lccc}
\hline Vrsta rabe $\left(\mathrm{m}^{2}\right)$ & Leto 1998 & Leto 2006 & Sprememba (\%) \\
\hline Njive in vrtovi & $570.427,21$ & $316.420,12$ & $-48,43$ \\
\hline Ekstenzivni sadovnjaki & $101.127,86$ & $110.284,32$ & $+9,05$ \\
\hline Trajni travniki & $16.945 .663,42$ & $16.980 .397,73$ & $+0,20$ \\
\hline Zemljišča v zaraščanju & $500.851,07$ & $677.216,96$ & $+35,21$ \\
\hline Drevesa in grmičevje & $404.382,52$ & $562.868,21$ & $+39,19$ \\
\hline Neobdelana kmetijska zemljišča & $62.386,60$ & $34.839,4517$ & $-44,16$ \\
\hline Kmetijske površine porasle z gozdnim drevjem & $307.671,05$ & $146.574,96$ & $-52,36$ \\
\hline Gozd & $62.800 .071,31$ & $62.983 .163,81$ & $+0,29$ \\
\hline Pozidana in sorodna zemljišča & $2.435 .285,04$ & $2.368 .778,17$ & $-2,73$ \\
\hline
\end{tabular}

Starost digitalnih ortofoto načrtov (DOF-ov), ki so se uporabljali pri inicialnem zajemu podatkov, je različna, najstarejši so iz leta 1997, najnovejši pa iz leta 2004. Med pripravo scenarijev so bili podatki za testno območje že ažurirani na podlagi DOF-ov iz leta 2006. Časovni interval med obema zajemoma podatkov sicer ni zelo velik, le osem let, če primerjamo s scenariji, ki zajemajo petnajstletno obdobje. Časovni interval je torej odvisen od dostopnosti podatkov. H. Briassoulis (2000) navaja, da pri markovskih modelih, ki pomenijo ekstrapolacijo spreminjanja $\mathrm{v}$ določenem časovnem intervalu na prihodnost, natančnost narašča s podaljševanjem obdobja med dvema zajemoma podatkov.

$\mathrm{V}$ predstavljenem primeru je poleg tega pomembna tudi prostorska natančnost oziroma merilo podatkov, saj spremljamo spremembe na relativno majhnem testnem območju. Kljub prostorski natančnosti podatkov o dejanski rabi zemljišč je mogoče opaziti razlike oziroma napake, ki izhajajo iz digitalizacije in opredelitve homogenih območij na podlagi DOF-ov. Opazne so razlike med zajemom leta 1998 in leta 2006, za katere ne moremo z gotovostjo trditi, ali pripadajo spremembi vrste rabe ali so posledica drugačnega načina dela in natančnosti pri zajemu podatkov (preglednica 2).

Spremembe površin določenih vrst rabe so dokaj skladne s splošnimi pričakovanji o spremembah kulturne krajine, kot so večanje deleža gozda, večanje deleža površin v zaraščanju, zmanjševanje intenzivno obdelanih kmetijskih površin, njiv in vrtov. Nekatere spremembe, ki bi jih lahko pričakovali, na primer večanje deleža pozidanih in sorodnih zemljišč, iz podatkov za testno območje kažejo drugačno težnjo. Površine so se med letoma 1998 in 2006 zmanjšale za $66.507 \mathrm{~m}^{2}$. Razliko je mogoče pojasniti z natančnejšo digitalizacijo podatkov za leto 2006, to tezo potrjuje tudi večje število opredeljenih poligonov za leto 2006. Iz primerjave klasifikacijskih ključev izhaja, da so bile $\mathrm{v}$ to kategorijo $\mathrm{v}$ prvem zajemu vključene posamezne površine trajnih travnikov in ekstenzivnih sadovnjakov v sklopu naselij ali ob njihovem robu oziroma vse parcele $\mathrm{z}$ različnimi vrstami rabe na robu naselja, ki so merile manj kot $1000 \mathrm{~m}^{2}$, pri novem zajemu v letu 2006 se glede na dejansko rabo (kot njive in vrtovi ali kot trajni travniki) opredeljujejo tudi manjše parcele, če kmetje zanje uveljavljajo pravico do kmetijsko okoljskih plačil. Med posameznima zajemoma podatkov je prišlo tudi do opustitve dveh kategorij, začasnih travnikov in gorskih pašnikov. Začasni travniki so se že do leta 2004 priključili kategoriji njive in vrtovi, gorski pašniki pa kategoriji trajni travniki. Pri kategoriji njive in vrtovi je za naše testno območje mogoče opaziti precejšnje zmanjšanje, in sicer za $48,43 \%$ med letoma 1998 in 2006. Veliko zmanjšanje gre deloma pripisati navodilom za zajemanje posameznih vrst rabe, ki se med obema zajemoma delno razlikujejo. Pri zajemu podatkov z DOF-ov iz 1998 so se travniki, ki so bili s treh strani obdani z njivami, šteli za začasne travnike, kasneje, ko se je ta kategorija opustila $\mathrm{v}$ vrsto rabe njive in travniki, pri digitalizaciji DOF-ov iz 2006, je bil zajem natančnejši ter so se kot njive in vrtovi opredelile le preorane površine, ostalo pa kot trajni travnik.

\subsection{Opredelitev prehodne matrike}

Prehodna matrika je zasnovana na podlagi ugotovljenih sprememb rabe tal $\mathrm{v}$ določenem časovnem intervalu, ta pa je navadno odvisen od dostopnosti podatkov. Za nadaljnje delo je bilo treba najprej opredeliti prehodne stopnje med posameznimi vrstami rabe in verjetnost prehoda iz enega $v$ drugo stanje (preglednica 3).

Površina in število zaplat posameznih vrst rabe je odvisna od natančnosti dosegljivih podatkov. Pri opredelitvi prehodne matrike površina oziroma število posameznih zaplat ne vpliva na rezultat. Pomembno pa je, da je v vsakem razredu dovolj enot, kar zagotavlja reprezentativnost verjetnosti spreminjanja za posamezne enote znotraj določene vrste rabe, še posebej če analiziramo le vzorec (Lawson, 1970). Enota, na katero se nanaša vrednotenje sprememb, je rastrska celica, kar nam omogoča uporaba rastrskih podatkov, za katere je značilno, da je v eni celici samo ena določena raba. Izbira rastrske celice za enoto tudi pomeni, da so vse enote enako velike. Lawson (1970) sicer navaja, da ni posebnega razloga, da bi morale biti enote enako 
Preglednica 3: Mogoči prehodi posameznih vrst rabe, ki obstajajo na testnem območju (ocena)

\begin{tabular}{|c|c|}
\hline Sedanja raba tal & Mogoče spremembe $v$ eni sekvenci \\
\hline \multirow{3}{*}{ Njive in vrtovi } & $\rightarrow$ njive in vrtovi \\
\hline & $\rightarrow$ ekstenzivni sadovnjaki \\
\hline & $\rightarrow$ trajni travniki \\
\hline \multirow{2}{*}{ Ekstenzivni sadovnjaki } & $\rightarrow$ ekstenzivni sadovnjaki \\
\hline & $\rightarrow$ zemljišča v zaraščanju \\
\hline \multirow{4}{*}{ Trajni travniki } & $\rightarrow$ trajni travniki \\
\hline & $\rightarrow$ neobdelana kmetijska zemljišča \\
\hline & $\rightarrow$ njive in vrtovi \\
\hline & $\rightarrow$ zemljišča v zaraščanju \\
\hline \multirow{3}{*}{ Zemljišča v zaraščanju } & $\rightarrow$ zemljišča v zaraščanju \\
\hline & $\rightarrow$ gozd \\
\hline & $\rightarrow$ pozidana in sorodna zemljišča \\
\hline \multirow{4}{*}{ Neobdelana kmetijska zemljišča } & $\rightarrow$ neobdelana kmetijska zemljišča \\
\hline & $\rightarrow$ zemljišča v zaraščanju \\
\hline & $\rightarrow$ trajni travniki \\
\hline & $\rightarrow$ pozidana in sorodna zemljišča \\
\hline \multirow{3}{*}{ Kmet. površine, porasle z gozdnim drevjem } & $\rightarrow$ kmetijske površine, porasle z gozdnim drevjem \\
\hline & $\rightarrow$ trajni travniki \\
\hline & $\rightarrow$ pozidana in sorodna zemljišča \\
\hline \multirow{2}{*}{ Drevesa in grmičevje (linijski element) } & $\rightarrow$ drevesa in grmičevje \\
\hline & $\rightarrow$ trajni travniki \\
\hline \multirow{2}{*}{ Gozd } & $\rightarrow$ gozd \\
\hline & $\rightarrow$ pozidana in sorodna zemljišča \\
\hline \multirow{2}{*}{ Pozidana in sorodna zemljišča } & $\rightarrow$ pozidana in sorodna zemljišča \\
\hline & $\rightarrow$ zemljišča v zaraščanju \\
\hline Vode & $\rightarrow$ vode \\
\hline
\end{tabular}

velike, vendar mora biti pri vsakem začetnem stanju posamezne kategorije zadostno število enot, da so izračunane verjetnosti prehodov za vsako kategorijo reprezentativne. Rastrsko celico sta kot osnovno enoto uporabila Stadelmann in Weiss (2007), z utemeljitvijo, da je rastrska celica najprimernejša enota pri uporabi markovskih modelov za analize spremembe rabe tal tam, kjer uporabljamo digitalne prostorske podatke.

Najprej smo s programom ArcInfo izračunali prehode med posameznimi rabami na osnovi sprememb števila celic posameznih vrst rabe. Na podlagi znane velikosti za celico in števila spremenjenih celic so bile izračunane površine posameznih sprememb. V nadaljevanju podajamo primer za spremembo vrste rabe trajnih travnikov.

Izračun verjetnostne matrike prehodov je preprost, vrednost posamezne celice $\mathrm{v}$ matriki prehodov (preglednica 4) delimo $\mathrm{z}$ vsoto vrednosti $\mathrm{v}$ istem stolpcu. Verjetnostna matrika pre- hodov podaja verjetnosti spreminjanja stanja iz ene rabe tal $\mathrm{v}$ drugo oziroma verjetnost, da raba $\mathrm{v}$ določenem obdobju ostane enaka.

$\mathrm{V}$ preglednici 4 so za ponazoritev podane površine prehodov iz vrste rabe trajni travniki v druge vrste rabe. V preglednici 5 so na podlagi površin prehodov za vse vrste rabe izračunane verjetnosti prehoda iz določene vrste rabe v druge vrste rabe v osemletnem obdobju, od leta 1998 do leta 2006. Površine prehodov iz posamezne vrste rabe $\mathrm{v}$ drugo so bile izračunane $s$ programom ArcGIS 9.2, na podlagi primerjave sprememb števila celic za posamezno vrsto rabe. Izračun frekvenčne matrike je bil izdelan na podlagi nemodificiranih podatkov, izvedli smo le združevanje kategorij (zaradi opustitve določene kategorije med zajemoma podatkov iz leta 1998 in leta 2006).

Predhodno smo že opozorili na določene nedoslednosti in razlike pri zajemu podatkov o dejanski rabi zemljišč za leti 1998 in 
Preglednica 4: Matrika prehodov - primer: spremembe vrste rabe trajnih travnikov med letoma 1998 in 2006

\begin{tabular}{ll}
\hline Spremembe iz trajnih travnikov v druge vrste rabe (1998-2006) & $\left(\mathrm{m}^{2}\right)$ \\
\hline Njive in vrtovi & $110.286,5$ \\
\hline Ekstenzivni sadovnjaki & $33.870,5$ \\
\hline Trajni travniki & 15.580 .250 \\
\hline Zemljišča v zaraščanju & 122.833 \\
\hline Drevesa in grmičevje & $107.350,3$ \\
\hline Neobdelana kmet. zemljišča & $18.667,5$ \\
\hline Kmet. površine, porasle z gozdnim drevjem & $56.905,25$ \\
\hline Gozd & 794.020 \\
\hline Pozidana zemljišča & $121.974,8$ \\
\hline Vode & 679,75 \\
\hline Vsota sprememb & $16.946 .837,5$ \\
\hline
\end{tabular}

2006. Ustrezna rešitev je uvedba modificiranega markovskega modela, s katerim smo pridobljene vrednosti po osnovni metodi preverili in korigirali na podlagi primerjave interpretacijskih ključev za leti 2006 in 1998 (Ministrstvo RS za kmetijstvo, gozdarstvo in prehrano, 2006b) (preglednica 6)".

Prilagodili smo te verjetnosti za vrste rabe:

- vode: izločili smo jih iz nadaljnje izdelave scenarijev, ker predvidoma pri tej vrsti rabe ni in tudi v prihodnje ne bo prihajalo do bistvenih sprememb; spremembe, prikazane $\mathrm{v}$ frekvenčni matriki, lahko pripišemo razlikam med obema zajemoma podatkov;

- pozidana in sorodna zemljišča: verjetnost spremembe v trajne travnike je manj verjetna, zato jo lahko delno pripišemo verjetnosti, da se vrsta rabe ne spremeni; verjetnost spremembe $\mathrm{v}$ gozd lahko pripišemo verjetnosti spremembe $\mathrm{v}$ zemljišča $\mathrm{v}$ zaraščanju, saj neposreden prehod iz pozidanih in sorodnih zemljišč v gozd poteka prek postopnega zaraščanja.

- njive in vrtovi: izjemno veliko spremembo (dve tretjini njiv in vrtov $\mathrm{v}$ trajne travnike $\mathrm{v}$ osmih letih) lahko pripišemo napakam pri interpretaciji, zaradi velike možnosti zamenjave trenutno zatravljenih njiv za trajni travnik; na podlagi ocene in ugotovljenega obsega napak pri klasifikaciji njiv in vrtov oziroma trajnih travnikov polovico verjetnosti za spremembo v trajne travnike $(0,33)$ prištejemo k verjetnosti, da se vrsta rabe ne spremeni.

- neobdelana kmetijska zemljišča: verjetnosti spremembe v vode zaradi izključitve vrste rabe vode pripišemo neobdelanim kmetijskim zemljiščem.

- kmetijske površine, porasle z gozdnim drevjem: verjetnost spremembe v gozd zmanjšamo na 0,05, razliko prištejemo $\mathrm{k}$ verjetnosti spremembe $\mathrm{v}$ zemljiišča v zaraščanje (ker sprememba poteka prek zaraščanja).

Kjer je verjetnost spremembe znašala le okoli 0,05, rezultatov nismo modificirali, saj dopuščamo manjše verjetnosti sprememb, prav tako tudi manjše napake, ki bi lahko nastale ob interpretaciji podatkov ali zaradi razlik med obema zajemoma podatkov.

Preglednica 5: Verjetnostna matrika prehodov (sprememba vrste rabe) za leti 1998 in 2006

\begin{tabular}{llllllllllllll}
\hline & 2006 & $A$ & $B$ & $C$ & $C$ & $D$ & $E$ & $F$ & $G$ & $H$ & $I$ & $\Sigma$ \\
\hline A & 0,34 & 0 & 0,66 & 0 & 0 & 0 & 0 & 0 & 0 & 0 & 1,00 \\
\hline$B$ & 0,00 & 0,45 & 0,40 & 0,00 & 0,02 & 0,00 & 0,03 & 0,06 & 0,03 & 0,00 & 1,00 \\
\hline$C$ & 0,01 & 0,00 & 0,92 & 0,01 & 0,01 & 0,00 & 0,00 & 0,05 & 0,01 & 0,00 & 1,00 \\
\hline$\check{C}$ & 0,00 & 0,00 & 0,21 & 0,52 & 0,04 & 0,00 & 0,00 & 0,22 & 0,00 & 0,00 & 1,00 \\
\hline $\mathrm{D}$ & 0,00 & 0,01 & 0,14 & 0,02 & 0,75 & 0,00 & 0,00 & 0,06 & 0,02 & 0,00 & 1,00 \\
\hline $\mathrm{E}$ & 0,00 & 0,00 & 0,65 & 0,09 & 0,00 & 0,19 & 0,00 & 0,04 & 0,00 & 0,04 & 1,00 \\
\hline $\mathrm{F}$ & 0,00 & 0,01 & 0,40 & 0,06 & 0,07 & 0,00 & 0,24 & 0,21 & 0,00 & 0,00 & 1,00 \\
\hline $\mathrm{H}$ & 0,00 & 0,00 & 0,01 & 0,00 & 0,00 & 0,00 & 0,00 & 0,99 & 0,00 & 0,00 & 1,00 \\
\hline $\mathrm{I}$ & 0,00 & 0,01 & 0,09 & 0,00 & 0,00 & 0,00 & 0,00 & 0,03 & 0,86 & 0,00 & 1,00 \\
\hline
\end{tabular}

Opomba: A - njive in vrtovi, B - ekstenzivni sadovnjaki, C - trajni travniki, Č - zemljišča v zaraščanju, D - drevesa in grmičevje, E - neobdelana kmetijska zemljišča, F - kmetijske površine, porasle z gozdnim drevjem, G - gozd, H - pozidana in sorodna zemljišča, I - vode. 
Preglednica 6: Modificirana verjetnostna matrika prehodov (sprememba vrste rabe) za leti 1998 in 2006

\begin{tabular}{|c|c|c|c|c|c|c|c|c|c|c|}
\hline 19 & $2006 \mathrm{~A}$ & B & C & $\check{C}$ & D & $E$ & $\mathrm{~F}$ & $\mathrm{G}$ & $\mathrm{H}^{\prime \prime}$ & $\Sigma$ \\
\hline$A$ & 0,67 & & 0,33 & & & & & & & 1,00 \\
\hline$B$ & & 0,45 & 0,40 & & 0,02 & & 0,03 & 0,06 & 0,03 & 1,00 \\
\hline$C$ & 0,01 & & 0,92 & 0,01 & 0,01 & & & 0,05 & 0,01 & 1,00 \\
\hline$\check{C}$ & & & 0,21 & 0,52 & 0,04 & & & 0,22 & & 1,00 \\
\hline$D$ & & 0,01 & 0,14 & 0,02 & 0,75 & & & 0,06 & 0,02 & 1,00 \\
\hline $\mathrm{E}$ & & & 0,65 & 0,09 & & 0,23 & & 0,04 & & 1,00 \\
\hline$F$ & & 0,01 & 0,40 & 0,22 & 0,07 & & 0,24 & 0,05 & & 1,00 \\
\hline G & & & 0,01 & & & & & 0,99 & & 1,00 \\
\hline $\mathrm{H}$ & & 0,01 & & 0,03 & & & & & 0,95 & 1,00 \\
\hline
\end{tabular}

Opomba: A - njive in vrtovi, B - ekstenzivni sadovnjaki, C - trajni travniki, Č - zemljišča v zaraščanju, D - drevesa in grmičevje, E - neobdelana kmetijska zemljišča, $\mathrm{F}$ - kmetijske površine, porasle z gozdnim drevjem, $\mathrm{G}$ - gozd, $\mathrm{H}$ - pozidana in sorodna zemljišča.

Napovedi za naslednjih 15 let izračunamo po spodnji enačbi (vrstični vektor $\mathrm{p}(\mathrm{n})$, ki pove, kolikšne so verjetnosti, da je sistem po $n$ korakih v stanju i). Ker je porazdelitev verjetnosti razen od prehodne matrike P odvisna le od predhodnega stanja, velja Chapman-Kolmogorova enačba (Hudoklin-Božič, 1999):

$\mathrm{p}(1)=\mathrm{p}(0) * \mathrm{P}$

$\mathrm{p}(2)=\mathrm{p}(1) * \mathrm{P}=(\mathrm{p}(0) * \mathrm{P}) * \mathrm{P}=\mathrm{p}(0) * \mathrm{P}^{2}$

$\mathrm{p}(3)=\mathrm{p}(2) * \mathrm{P}=(\mathrm{p}(1) * \mathrm{P}) * \mathrm{P}=((\mathrm{p}(0) * \mathrm{P}) * \mathrm{P}) * \mathrm{P}=\mathrm{p}(0) * \mathrm{P}^{3}$

...

$\mathrm{p}(\mathrm{n})=\mathrm{p}(0) * \mathrm{P}^{\mathrm{n}}$

Verjetnostna matrika prehodov $(\mathrm{P})$ podaja verjetnosti za prehode iz enega $\mathrm{v}$ drugo stanje $\mathrm{v}$ enem koraku, ki je dolg osem let. Za izdelavo scenarijev nas zanima petnajstletno obdobje, ker podatki prikazujejo stanje v letu 2006, pa v bistvu šestnajstletno obdobje, ki je dvakratnik koraka dolžine osem let, zato $\mathrm{v}$ našem primeru velja enačba: $\mathrm{p}(3)=\mathrm{p}(2) * \mathrm{P}=(\mathrm{p}(1) * \mathrm{P}) * \mathrm{P}=((\mathrm{p}(0) * \mathrm{P}) * \mathrm{P}) * \mathrm{P}=\mathrm{p}(0) * \mathrm{P}^{3}$,

če vzamemo za izhodiščno stanje leto 1998 oziroma

$\mathrm{p}(2)=\mathrm{p}(1) * \mathrm{P}=(\mathrm{p}(0) * \mathrm{P}) * \mathrm{P}=\mathrm{p}(0) * \mathrm{P}^{2}$,

če je izhodiščno stanje leto 2006. Zaradi razlik med zajemoma je priporočljivo narediti oba izračuna in rezultata primerjati. Izračuni so bili narejeni s programom za izračun matrik, dostopnem na strežniku wims (http://wims.unice.fr), podatki pa so bili predhodno obdelani s programom ArcInfo 9.2 in Excel.

\section{Rezultati}

$\mathrm{V}$ preglednici 7 sta predstavljena različna načina izračuna površin posameznih vrst rabe za leto 2022. Pri prvem so uporabljeni podatki iz leta 1998, pri drugem iz leta 2006 ter ustrezno število obdobij oziroma korakov, ki se izraža kot potenca koraka p. Za nadaljnjo izdelavo scenarija smo izbrali izračun z mo-

Preglednica 7: Različna načina izračuna površin vrst rabe za leto 2022

\begin{tabular}{lrr}
\hline Površine vrst rabe $\left(\mathrm{m}^{2}\right)$ & $\mathrm{p}(2022)=\mathrm{p}(1998) * \mathrm{p}^{3}$ & $\mathrm{p}(\mathbf{2 0 2 2})=\mathrm{p}\left(\mathbf{2 0 0 6 )} * \mathrm{P}^{2}\right.$ \\
\hline Njive in vrtovi & $538.414,94$ & $422.835,88$ \\
\hline Ekstenzivni sadovnjaki & $61.042,68$ & $67.235,10$ \\
\hline Trajni travniki & $16.269 .599,31$ & $16.401 .922,75$ \\
\hline Zemljišča v zaraščanju & $557.455,35$ & $594.519,81$ \\
\hline Drevesa in grmičevje & $630.175,89$ & $670.547,53$ \\
\hline Neobdelana kmetijska zemljišča & 759,06 & 1843,01 \\
\hline Kmetijske površine porasle z gozdnim drevjem & 6947,70 & $11.649,14$ \\
\hline Gozd & $63.911 .861,74$ & $63.787 .264,82$ \\
\hline Pozidana in sorodna zemljišča & $2.601 .429,04$ & $2.495 .266,37$ \\
\hline Vode & $/$ & $/$ \\
\hline Skupna površina & $84.577 .685,71$ & $84.453 .084,41$
\end{tabular}


Preglednica 8: Izračunana sprememba površin po posameznih vrstah rabe

\begin{tabular}{lcc}
\hline Vrsta rabe & Sprememba površine $(2006-2022)$ \\
\cline { 2 - 3 } & $\left(\mathrm{m}^{2}\right)$ & 33,63 \\
\hline Njive in vrtovi & $+106.415,76$ & $-39,03$ \\
\hline Ekstenzivni sadovnjaki & $-43.049,22$ & $-3,41$ \\
\hline Trajni travniki & $-578.474,98$ & $-12,21$ \\
\hline Zemljišč v zaraščanju & $-82.697,15$ & 19,13 \\
\hline Drevesa in grmičevje & $+107.679,32$ & $-94,71$ \\
\hline Neobdelana kmet. zemljišča & $-32.996,45$ & $-92,05$ \\
\hline Kmetijske površine, porasle z gozdnim drevjem & $-134.925,82$ & 1,28 \\
\hline Gozd & $+804.101,01$ & 5,33 \\
\hline Pozidana in sorodna zemljišča & $+126.240,12$ & \\
\hline
\end{tabular}

dificiranimi vhodnimi podatki za leto 2006 (v preglednici 7 je označen s krepkim tiskom). Izračun z novejšimi podatki je pravilnejši, saj je bila metodologija zajema podatkov v 2006 natančnejša in smo se z njo lahko izognili določenim napakam, ki jih vsebujejo podatki za leto 1998.

Preglednica 8 prikazuje izračun sprememb površin rabe med letoma 2006 in 2022 po metodi markovskih verig. Izstopa povečanje njiv in vrtov za dobro tretjino (10 ha), pri tem dodajamo, da kategorija zajema tudi hišne vrtove, katerih površine se bodo s širitvijo stanovanjske pozidave verjetno povečale. Pri zmanjšanju površine ekstenzivnih sadovnjakov gre večinoma za obraten proces, pri katerem se bodo sadovnjaki v bližini naselja zmanjšali zaradi širitve pozidave; dejansko sprememba ni tako obsežna, saj pomeni le okoli 4 hektarje zemljiščc.

Stanovanjske površine naj bi se povečale za 12 ha. Predvideno je zmanjšanje trajnih travnikov ( $57 \mathrm{ha}$ ) in površin v zraščanju (8 ha), neobdelanih kmetijskih zemljišč (3 ha) in kmetijskih zemljišč, poraslih z gozdnim drevjem (13 ha), kar lahko v največji meri pripišemo povečanju deleža gozda za 1,28 \% oziroma 80 hektarjev.

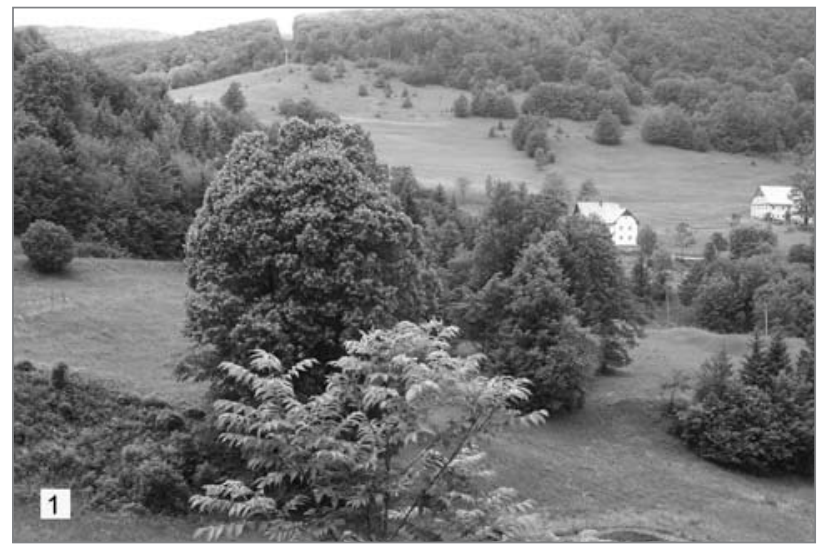

Izračunane spremembe površin rabe smo dopolnili z razvojnimi smernicami za tesno območje (Bizjak, 2005; Bizjak, 2006) ter oblikovali pisni scenarij, ki podaja stanje pomembnih vrst rab v testnem območju čez 15 let in vključuje spremembe, ki jih navajajo razvojni dokumenti, kot so: izgradnja obvoznice, spodbujanje izkoriščanja biomase, razvoj storitvenih in obrtnih dejavnosti. Scenarij in fotomontaže smo uporabili v anketni raziskavi, ki je zajemala vse nosilce kmetijskih gospodarstev $s$ testnega območja. V raziskavi smo preverjali vpliv scenarijev na stališča glede sprememb kulturne krajine in posledičnih sprememb ravnanja. Scenarij in fotomontaže, ki ponazarjajo spremembe, opisane v scenariju, predstavljamo v nadaljevanju.

\section{Scenarij za območje krajevnih skupnosti Godovič in Črni Vrh čez 15 let}

Na območju Godoviča se je povečala gostota stanovanjske pozidave. $Z$ enodružinskimi hišami so zapolnjena prosta stavbna zemljišča znotraj naselja in ob robu naselja, obrtna cona je razširjena. V Godoviču je zgrajena obvoznica, cesta GodovičKalce je prilagojena za višje hitrosti. V naselju Črni Vrh je zgrajenih več novih stanovanjskih objektov. $V$ drugih manjših

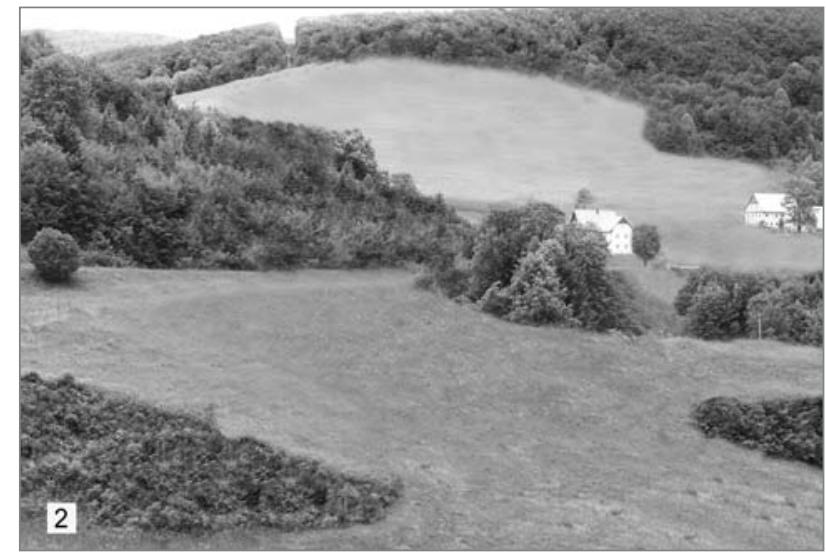

Slika 2: 1 - fotografija stanja v letu 2006; 2 - fotomontaža scenarija (foto: Damjana Gantar). 
zaselkih so zgrajene posamezne hiše in gospodarska poslopja oziroma so obnovljeni starejši objekti. Skupno so se pozidane površine povečale za dobrih 10 odstotkov. V naseljih Godovič in Črni Vrh sta manjša oskrbna centra s trgovinami, z gostinsko dejavnostjo, $s$ poštnimi in $z$ bančnimi storitvami. $V$ odprtem prostoru so se površine $\mathrm{v}$ zaraščanju zmanjšale za približno 10 \%. Le majhen del (okoli 10 \%) kmetijskih zemljǐšc, ki je bil neobdelan oziroma v zaraščanju, ostaja neobdelan. Čiščenje zaraščenih površin ter odstranjevanja grmičevja in drevja na kmetijskih površinah poteka predvsem zaradi pridobivanja biomase. Travniške površine se niso bistveno spremenile, zmanjšale so se za $3 \%$, obseg se vzdržuje $s$ košnjo in pašo. Površina gozda se je povečala za $1 \%$. Površine njiv in vrtov, ki vključujejo tudi vrtove ob hišah, so spremenljivejše, mogoče je povečanje celo do $30 \%$. Za dobrih $30 \%$ so se zmanjšale površine sadovnjakov, predvsem na račun gradnje znotraj naselij in ob robu teh.

\section{Sklep}

Opisani primer uporabe markovskih verig za izdelavo scenarija razvoja kulturne krajine je predstavitev uporabe metode, ki se sicer pogosteje uporablja za napovedovanje sprememb v določenem časovnem obdobju, kadar podatki niso »prostorski«. Rezultat uporabe metode je verjetnost za določeno spremembo, na podlagi katere izračunamo tudi predviden obseg spremembe. Pri prostorskih podatkih nas navadno najbolj zanima, kje se bodo določene spremembe zgodile, na primer, kje je verjetno, da se bodo travniške površine spremenile v površine $\mathrm{v}$ zaraščanju, ali katere površine se bodo spremenile $\mathrm{v}$ pozidana zemljišča. Izračun z uporabo markovskih metod nam te $\gg$ alokacije « ne more podati. Kakor so ugotovili tudi B. Kovačič in drugi (2007), ki so spremembe različnih vrst rab izračunali s programom Idrisi, je treba za alokacijo prostorskih sprememb v program vnesti določena pravila oziroma omejitve (npr. območja, ki so primerna za poselitev), torej izdelati model, po katerem program spremembe določene vrste rabe umesti v prostor. Zaradi istega razloga je U. Tappeiner (2007) za dopolnitev scenarijev, izdelanih po metodi markovskih verig, uporabila scenarije, ki so jih v okviru delavnic oblikovali deležniki. Metoda makovskih modelov je relativno preprosta za uporabo in jo lahko uporabljamo za analizo časovne dinamike pojavov z najrazličnejših področij. Največji problem, ki ga pri uporabi markovskih verig za prostorsko vezane podatke omenja več avtorjev (Lawson, 1970; Mežan, 1995; Gantar, 2009) je dostopnost primerljivih prostorskih podatkov z ustrezno časovno vrsto. Od kakovosti podatkov je namreč v največji meri odvisna natančnost napovedanih verjetnosti za spremembe.

Metoda markovskih verig se je kljub temu izkazala za uporabno in pregledno, $\mathrm{v}$ primerjavi $\mathrm{z}$ enostavnejšo metodo linearne ekstrapolacije, ki se je v tem primeru izkazala za neuporabno.
Z izračunom po metodi markovskih verig smo dobili rezultate, ki so bili za večino kategorij prostorske rabe sprejemljivi in verjetni. Pri vrstah rabe, pri katerih rezultati niso bili pričakovani, je mogoče na podlagi poznavanja vzrokov odstopanj, kot so razlike $\mathrm{v}$ interpretaciji podatkov in nekatere napake, ki jih je mogoče preveriti na terenu oziroma s primerjavo $z$ drugimi dostopnimi podatki, podatke prilagoditi oziroma preoblikovati. Pri zasnovi scenarija smo izvedli takšno preoblikovanje in s tem izboljšali končne rezultate. Na podlagi izračunov smo napisali scenarij v obliki zgodbe ter spremembe ilustrirali z uporabo fotografij sedanjega stanja in fotomontaž scenarija. Scenarij, predstavljen v članku, ni bil namenjen samo podrobnejši opredelitvi verjetnih prihodnjih sprememb v prostoru, temveč je služil kot orodje za proučitev odziva med uporabniki, ki so sodelovali v raziskavi. Za uporabo scenarija v raziskavi vpliva scenarijev na stališča bi sicer zadoščal tudi scenarij, napisan povsem intuitivno, vendar je uporabljeni scenarij objektivnejši. Med raziskavo se je izkazalo tudi, da so predstave o prihodnosti sodelujočih v raziskavi, ki v prostoru dejansko živijo in ga obdelujejo, precej skladne s predvidevanji, opisanimi v scenariju.

Damjana Gantar, univ. dipl. inž. kraj. arh., asistentka

Urbanistični inštitut Republike Slovenije, Ljubljana, Slovenija

E-pošta:damjana.gantar@uirs.si

\section{Opombe}

${ }^{[1]}$ Doktorsko delo, pod mentorstvom doc. dr. Mojce Golobič, Oddelek za krajinsko arhitekturo Biotehniške fakultete Univerze v Ljubljani.

\section{Viri in literatura}

Basharin G. P., Langville A. N., in Naumov V. A. (2005): The life and work of A. A. Markov. Dostopno na: http://decision.csl.uiuc. edu/ meyn/pages/Markov-Work-and-life.pdf (sneto 10. 5. 2007)

Bizjak, R. (2005): Razvojni program območja doline reke Idrijce. Idrija, Studio 3, d. o. o., Koda, d. o. o, Icra, d. o. o.

Bizjak, R. (2006): Strokovne podlage za poselitev občine Idrija. Idrija, Koling, d. o. o., Občina Idrija.

Briassoulis, H. (2000): Analysis of land use change: Theoretical and modelling approaches. Dostopno na: http://www.rri.wvu.edu/WebBook/Briassoulis (sneto 6. 6. 2007).

Gantar, D. (2009): Scenarij razvoja kulturne krajine kot dejavnik spreminjanja stališč in ravnanja deležnikov. Doktorska disertacija. Ljubljana, Univerza v Ljubljani, Biotehniška fakulteta, Oddelek za krajinsko arhitekturo.

Hudoklin-Božič, A. (1999): Stohastični procesi. Kranj, Moderna organizacija.

Jamnik, R. (1987): Verjetnostni račun. Ljubljana, Društvo matematikov, fizikov in astronomov SRS, Zveza organizacij za tehnično kulturo Slovenije.

Kovačič, B., Kranjc, M., Primožič, T. Sajovic, T., in Tomšič, A. (2007): 
Uporaba Markovskih verig in podpore odločanja na primeru Slovenije. Raziskovalno poročilo. Ljubljana, Univerza v Ljubljani, Filozofska fakulteta, Oddelek za geografijo.

Lawson, B. R. (1970): An application of Markov Chains to an analysis of the growth and decline of settlements in the Ljubljana metropolitan area. American-Yugoslav project in regional and urban planning studies. Ljubljana, Urbanistični inštitut SR Slovenije.

Mežan, U. (1995): Napovedovanje poškodovanosti gozdov z uporabo modela markovskih verig. Diplomsko delo. Ljubljana, Univerza v Ljubljani, Biotehniška fakulteta, Oddelek za gozdarstvo.

Ministrstvo RS za kmetijstvo, gozdarstvo in prehrano (1998): Kataster dejanske rabe kmetijskih zemljišč (RABA). Izpis iz baze podatkov. Ljubljana.

Ministrstvo RS za kmetijstvo, gozdarstvo in prehrano (2006a): Kataster dejanske rabe kmetijskih zemljišč (RABA). Izpis iz baze podatkov. Ljubljana.

Ministrstvo RS za kmetijstvo, gozdarstvo in prehrano (2006b): Interpretacijski ključ. Podroben opis metodologije zajema dejanske rabe kmetijskih in gozdnih zemljišč. Ljubljana.

Omladič, V. (1993): Application of interactive Markov models in the dynamics of social systems. Dostopno na: http://www.sisplet.org/ index.php? $\mathrm{fl}=28 \mathrm{lact}=18 \mathrm{bid}=197 \&$ avtor $=172 \&$ parent $=30$ (sneto 7. 5. 2007)

Shearer, A. W. (2005): Approaching scenario based studies: Three perceptions about the future and considerations for landscape planning. Environment and Planning B: Planning and Design, 32(1), str. 67-87.

Shoemaker, P. J. H. (1993): Multiple scenario development: Its conceptual and behavioral foundation. Strategic Management Yournal, 14(3), str. 193-213.

Stadelmann, G., in Weiss, M. (2007): Modelierung der zukünftigen Landnutzung in der Surselva. Zürich, Eidgenössische Technische Hochschule, Swiss Federal Institute of Technology.

Steinitz, C., Arias Rojo, H. M., Basset, S., Flaxman M., Goode, T., Maddock III, T., idr. (2003): Alternative futures for changing landscapes. The Upper San Pedro river basin in Arizona and Sonora. Washington D.C., Island Press.

Tappeiner, U. (2007): Land use change in the European Alps: Effects of historical and future scenarios of landscape development on ecosistem services. Dostopno na: http://epub.oeaw. ac.at/0xc1aa500d_0x0016f3a1.pdf (sneto 29. 1. 2009)

Veeneklaas, F. R., in van den Berg, L. M., 1995: Scenario building: Art, craft or just a fashionable whim? V: Schoute, J. F. T., Finke, P. A., Veeneklaas, F. R., in Wolfert, H. P. (ur.): Scenario studies for the rural environment, str. 11-13. Dordrecht, Kluwer academic publishers. 